\title{
Effect of peritoneal dialysis on the dynamic functions of the diaphragm
}

\author{
Supraja K*, Arulneyam J, Rajeevalochana P, Sharmila S, Karthick N and Abraham G \\ Department of Clinical Research, The Madras Medical Mission, Chennai, India
}

\begin{abstract}
Aim: Peritoneal dialysis (PD) is an accepted mode of renal replacement therapy in chronic kidney disease (CKD) patients. With increasing longevity, the duration of $\mathrm{PD}$ goes up to several years. Diaphragm is the most important muscle for inspiration during resting state. The functions of this muscle can be assessed by invasive electromyography and stimulation of phrenic nerve. In this study, we have recorded the neural function with Surface Electromyography (SEMG).

Objective: This is a prospective study in patients undergoing chronic PD. We set to find out if diaphragm movement was affected in patients on peritoneal dialysis and compared it with the diaphragm movement in hemodialysis patients. Secondly, we looked for impact of diaphragmatic movements on the ultrafiltration.

Methods: CKD patients enrolled on PD for more than 3 months were observed for diaphragmatic movements (surface EMG of diaphragm, NCS), airway function (PFT) and PD characteristics (ultrafiltration amount, percentage of dialysate, urine output and Serum Hemoglobin, Albumin). Volume of dwell in all subjects was 2 liters and dwell time varied between 6-8 hours.

Results: Thirty-six patients underwent the study with 12 females and 24 males. The duration of PD varied between 3 months to 16 years. Mean age was 60.3 (SD \pm 14.4). The mean resting EMG of diaphragm in PD subjects was $13.7 \mu \mathrm{V}$ and in hemodialysis subjects was $13.47 \mu \mathrm{V}$ (Normal:10-20 $\mu \mathrm{V}$ ). Nine subjects were on $2 \mathrm{~L}$ icodextrin as single dwell. NCS of phrenic nerve was abnormal in most subjects. Association of SEMG was significant for Gender (p 0.007), BMI (p 0.00), FEV1 ( $\mathrm{p} 0.00)$ and hemoglobin (0.0059). Logistic regression analysis showed negative association between gender and hemoglobin. No correlation was observed between diaphragm movement and ultrafiltration and residual renal function.

Conclusion: We conclude that diaphragmatic EMG is preserved in subjects undergoing CAPD and is comparable with that of subjects in HD group. Even though NCS of phrenic nerve showed severe sensory-motor neuropathy in most PD patients, normal resting surface EMG highlights the fact that intrinsic muscle action potential is retained. There is no impact of diaphragmatic movement on the ultrafiltration irrespective of the concentration of dialysate used in PD. Also, we hypothesize that sensory-motor neuropathy is probably is secondary to diabetes rather than due to CAPD.
\end{abstract}

\section{Introduction}

Continuous ambulatory Peritoneal Dialysis (CAPD) has become an accepted method of renal replacement in chronic kidney disease (CKD), and the number of subjects on PD is on the rise. Without complications, these catheters can be maintained and used for many years. The abdomen is presumed to accommodate large quantities of fluid without producing significant respiratory distress. In CAPD, the number of bags used, the percentage of the dialysate and duration of the dwell is determined by the residual renal function and the ultrafiltration. Hence, these subjects have a dwell of minimum 2 Liters for at least 4-16 hours a day.

Studies in the past have assessed respiratory mechanics in patients with abdominal fluid and have established that there is no change in the airflow or gas exchange [1-3].

Sensory motor neuropathy is high in such subjects due to CKD per se and due to the associated Diabetic status. This can affect all the muscles including the diaphragm [4]. The presence of the dwell for a considerable part of the day and the underlying neuropathy can impair the functions of the diaphragm. The neuro-mechanical efficiency of the diaphragm in 8 CAPD patients was assessed by Wanke et al. [5] using trans diaphragmatic pressure (Pdi) and EMG (EMGdi) and found that it was impaired in the filled state.
All studies done in the past have used invasive techniques for measuring the diaphragm EMG. With the emergence of Surface EMG, studying the diaphragm has been simplified and avoids complications such as Pneumothorax [6]. In our study, we have used SEMG to obtain the muscle electrical potential of both the diaphragms. SEMG is easy to perform, noninvasive and reproducible [7] (Figure 1).

\section{Study designs and subjects}

This is a prospective, observational, single center study of subjects undergoing PD in the Department of Nephrology, The Madras Medical Mission, Chennai. We included 36 subjects on PD above the age of 18 years and on PD for minimum duration of 3 months. We excluded subjects with history of diaphragm palsy, history of Peritonitis in previous 3 months, Chronic obstructive pulmonary disease, Gullian Barre Syndrome, Chronic Inflammatory Demyelinating Polyneuropathy, old Pulmonary Tuberculosis, lung trauma, previous history of spinal cord

*Correspondence to: Supraja Kalyanaraman, Department of Clinical Research, The Madras Medical Mission, 4-A, Dr. J. Jayalalitha Nagar, Mogappair, Chennai-600037, India, Tel: 950-004-9868; E-mail: drsk02@gmail.com

Received: January 10, 2019; Accepted: February 18, 2019; Published: February 21,2019 


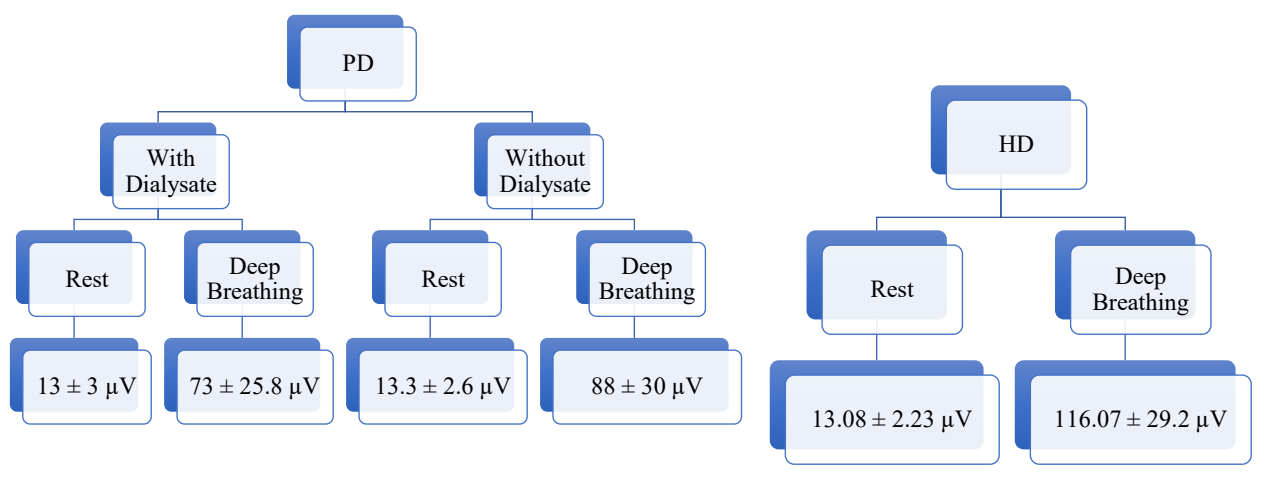

Figure 1. SEMG of diaphragm

injury and malignancy. 23 subjects on maintenance hemodialysis were also examined for diaphragm movements.

\section{Methodology}

The following data were captured: age (years), BMI $\left(\mathrm{Kg} / \mathrm{m}^{2}\right)$, Comorbidities, Surface EMG (SEMG) of diaphragm, Nerve conduction study (NCS), Pulmonary Function Test (PFT), PD characteristics (ultrafiltration amount, percentage of dialysate, urine output), Serum Hemoglobin, Albumin, Electrolytes, Serum Calcium and Serum Phosphorous.

\section{Neurological examination}

All subjects in PD group were examined by the Neurologist for clinical examination; nerve conduction study was done using ALERON RMS 401 Chandigarh, India. SEMG was done with Medicaid Systems, Neurostim, Portable EEG, India. SEMG recordings were done twice - before filling PD fluid and before draining out PD fluid, with subjects lying at 45 degrees. The electrodes were fixed to the skin using adhesive tapes to reduce the friction and signal impedance. SEMG was performed with 2 electrodes on the dermis surface at the right and left costal margin $1.5 \mathrm{~cm}$ away from the Xiphoid and 2 electrodes at the back at the same height. The ground electrode was placed at the Sternum. Electrical activity was recorded for 10 seconds at rest and during deep breathing. The measurements were recorded on a laptop, with recorded numbers representing the surface EMG values. Twenty three subjects on hemodialysis also underwent SEMG after hemodialysis during rest and during deep breathing.

\section{Respiratory examination}

Subjects underwent Pulmonary function test using KoKo Spirometer and assessed for FEV1 (L/s).

All subjects signed the Consent form approved by the Institutions Ethics Committee. Statistical analysis was done using Epi Info software for Windows (version 7.2.2, CDC, Atlanta) with significance level of $P$ $<0.05$. Paired t test was done using SPSS 12 (IBM, New York, USA) for group comparisons.

\section{Results}

During the study period, 36 subjects in the PD group (12 females and 24 males) and 23 in the HD group (7 females and 16 males) underwent SEMG. Subjects in the study had varying duration of CAPD (3 months -16 years). The demographics and baseline characteristics are shown in table 1 . Mean age of the PD group was $60.3 \pm 14$ years. The SEMG of diaphragm, with and without dialysate while at rest was $13 \pm$ $3 \mu \mathrm{V}$ (2 tailed sig 0.357) (normal $10-20 \mu \mathrm{V}$ ) and deep breathing was 88
Table 1. Demographics and baseline characteristics

\begin{tabular}{|l|c|c|}
\hline Parameter & Frequency & P value \\
\hline Age (years) & $60.3 \pm 14$ & 0.56 \\
\hline Males & $24(66.67 \%)$ & 0.0069 \\
\hline BMI $\left(\mathrm{Kg} / \mathrm{m}^{2}\right)$ & $25.36 \pm 4.67$ & 0.0000 \\
\hline Diabetes Mellitus & $19(52.78 \%)$ & 0.1126 \\
\hline Hypertension & $33(91.67 \%)$ & 0.53 \\
\hline Coronary Artery Disease & $20(55.56 \%)$ & 0.99 \\
\hline Hypothyroid & $11(30.56 \%)$ & 0.45 \\
\hline Duration of PD (months) & $32.16( \pm 43)$ & 0.77 \\
\hline Ultrafiltration $(\mathrm{ml})$ & $1306 \pm 422$ & 0.051 \\
\hline Urine output $(\mathrm{ml})$ & $459.72 \pm 391$ & 0.60 \\
\hline Right Phrenic NCS (mV) & $1.14 \pm 0.61$ & 0.78 \\
\hline Left Phrenic NCS (mV) & $1.20 \pm 0.60$ & 0.76 \\
\hline FEV1 (L/s) & $0.63 \pm 0.16$ & 0.00 \\
\hline Serum Albumin $(\mathrm{mg} / \mathrm{dL})$ & $3.21 \pm 0.5$ & \\
\hline Hemoglobin $(\mathrm{g} / \mathrm{dL})$ & $10.45 \pm 2.12$ & 0.0059 \\
\hline Serum Sodium (mg/dL) & $133.88 \pm 5.03$ & 0.29 \\
\hline Serum Potassium (mg/dL) & $4.13 \pm 0.8$ & 0.72 \\
\hline Serum Bicarbonate (mg/dL) & $25.80 \pm 2.2 .4$ & 0.66 \\
\hline Serum Chloride (mg/dL) & $93.91 \pm 5.32$ & \\
\hline Serum Calcium (mg/dL) & $9.29 \pm 2.47$ & 0.40 \\
\hline Serum Phosphorous (mg/dL) & $4.75 \pm 1.37$ & 0.96 \\
\hline & & \\
\hline
\end{tabular}

$\pm 30 \mu \mathrm{V}$ (2 tailed sig 0.096); null hypothesis accepted stating there is no difference between the groups. Hence, all analysis was done based on the resting diaphragmatic SEMG with Dialysate.

Clinical Neurological examination and Nerve conduction study showed sensory motor neuropathy in 34 subjects (19 were diabetics and 19 non-diabetics). The NCS of the phrenic nerve was abnormal (R $1.44 \pm 0.61 \mathrm{mV}$ and L $1.20 \pm 0.60 \mathrm{mV}$ ). SEMG across the vintage of CAPD was similar ( $\mathrm{p} 0.77$ ), thus defying the fact that with prolonged exposure to fluid in the abdomen impairs the neural functions of the diaphragm. The SEMG of HD group was - at rest $(13.08 \pm 2.2 \mathrm{mV})$ and deep breathing $(116.07 \pm 29.2 \mathrm{mV})$, almost like the PD group.

Significant association was observed between SEMG and gender (p 0.0069), BMI (0.00), FEV1 (p 0.00) and Hemoglobin (p 0.0059). However, logistic regression analysis was significant for $\mathrm{Hb}$ and gender.

\section{Discussion}

This prospective study aimed to evaluate whether the diaphragm functions are intact in subjects undergoing CAPD using SEMG. In our study, we have established that the SEMG of the diaphragm is intact and does not change with prolonged duration on CAPD. Also, the SEMG is similar when compared to chronic kidney disease patients on Hemodialysis. 
The clinical and Nerve conduction study showed severe sensory motor neuropathy in most subjects. However, the inherent electrical potential of the muscle is retained and intact even after 10 years of PD. Similarly, the diaphragm SEMG was well preserved in the HD group. This finding gives a new insight diaphragm neuro-mechanical function is maintained across all dialysis patients and probably explains the theory put forth by Bush et al. [8] that diaphragm adapts to a new force-length relationship to compensate for the chronic changes (lengthening) in its resting length due to CAPD

FEV1 observed were within normal limits. This finding is in concurrence with previous studies that airflow is also unaffected in CAPD subjects. Mactier et al. [9] had proposed that perhaps increased movements of the diaphragm might reduce the ultrafiltration secondary to increased lymphatic absorption; in our study, we observe that there is association between deep breathing and change in ultrafiltration however it is not statistically significant.

We have employed SEMG for the first time to study the neuro mechanical efficiency of the diaphragm. Although needle EMG or trans-diaphragmatic EMG is the gold standard, SEMG has been shown to be relatively easy to perform and has good repeatability [10].

\section{Conclusion}

Neuro mechanical functions of the diaphragm are intact in subjects undergoing chronic PD and is comparable with those of Hemodialysis subjects. Surface EMG is a simpler and efficient method to study the diaphragm electrical potentials. The movements of the diaphragm did not have an impact on the ultrafiltration.

\section{References}

1. Berkowitz KA, Butensky MS, Smith RL (1993) Pulmonary function changes after large volume paracentesis. Am J Gastroenterol 88: 905-907. [Crossref]

2. Almeida CP, Ponce D, de Marchi AC, Balbi AL (2014) Effect of peritoneal Dialysis on respiratory Mechanics in Acute Kidney Injury patients. Perit Dial Int 34: 544568 .

3. Ulubay G, Sezer S, Ulasli S, Ozdemir N, Eyuboglu OF, et al. (2006) Respiratory evaluation of patients on continuous ambulatory peritoneal dialysis prior to renal transplantation. Clin Nephrol 66: 269-274. [Crossref]

4. Bark H, Heimer D, Chaimovitz C, Mostoslovski M (1998) Effect of chronic renal failure on respiratory muscle strength. Respiration 54: 153-161. [Crossref]

5. Wanke T, Auinger M, Lahrmann H, Merkle M, Formanek D, et al. (1994) Diaphragmatic function in patients on continuous ambulatory peritoneal dialysis. Lung 172:231-240. [Crossref]

6. Sarwal A, Walker FO, Cartwright MS (2013) Neuromuscular Ultrasound for Evaluation of the Diaphragm. Muscle Nerve 47: 319-329. [Crossref]

7. GT Allison, K Kendle, S Roll, J Schupelius Q Scott, et al. (1998) The role of the diaphragm during abdominal hollowing exercises. Aust J Physiother 44: 95-102. [Crossref]

8. Bush A, Miller J, Peacock AJ, Sopwith T, Gabriel R, et al. (1985) Some observations on the role of the abdomen in breathing in patients on peritoneal dialysis. Clin Sci 68: 401-406. [Crossref]

9. Mactier RA, Khanna R, Twardowski ZJ, Nolph KD (1987) Role of peritoneal cavity lymphatic absorption in peritoneal dialysis. Kidney Int 32: 165-172. [Crossref]

10. Maarsingh EJ, van Eykern LA, Sprikkelman AB, Hoekstra MO, van Aalderen WM (2000) Respiratory muscle activity measured with a non-invasive EMG technique: technical aspects and reproducibility. J Appl Physiol 88: 1955-1961. [Crossref]

Copyright: (C2019 Supraja K. This is an open-access article distributed under the terms of the Creative Commons Attribution License, which permits unrestricted use, distribution, and reproduction in any medium, provided the original author and source are credited. 